\title{
: FAMÍLIA E HOSPITAL-DIA: INTERVENÇÕES DENTRO E FORA
}

\author{
Jorge Fouad Maalouf \\ Mira Wajntal
}

民

1 ste artigo apresenta o Hospital-Dia Infantil de Saúde Mental da Mooca, São Paulo, dispositivo institucional construído para o atendimento intensivo em saúde mental à infância. $\mathrm{Na}$ primeira parte, Maalouf faz um panorama sobre a política de saúde mental que embasou a construção deste equipamento e alguns princípios norteadores da clínica desenvolvida com as crianças e seus familiares. Destaca a atividade cultural como um exemplo da relação que a equipe propõe, dentro ou fora do Hospital-Dia, para articulação das crianças e seus familiares no circuito social, discutindo seus manejos, repercussões e resultados, tanto clínicos quanto institucionais. Na segunda parte deste texto, Wajntal discute como todo dispositivo institucional tem uma concepção de cura subjacente, que determina não só o funcionamento da instituição, como a prática clínica de seus profissionais. Descreve a especificidade clínica da psicose na infância e ilustra as repercussões deste dispositivo na dinâmica de um caso clínico.

\section{ATIVIDADE CULTURAL: INVENTANDO JUNTO COM AS FAMÍLIAS}

O Hospital-Dia Infantil da Mooca, onde trabalhei de janeiro de 1992 até junho de $1996^{1}$, foi criado pela Secretaria Municipal de Saúde de São Paulo, na gestão 1989-1992. O projeto Hospital-Dia foi implantado a partir de uma política de Saúde $\mathrm{Mental}^{2}$ que considerava importante a interação social, o respeito e o direito à cidadania das pessoas que vivenciam um sofrimento psíquico intenso, necessitando, portanto, de um dispositivo institucional propiciador de continência, atividades e vínculos em ritmo e freqüência intensivos. Esta concepção de tratamento é uma al-

Psicólogo, Mestrando em Psicologia Clínica na Pontifícia Universidade Católica de São Paulo

Psicanalista, Pós-graduanda em Psicologia Clínica na Pontificia Universidade Católica de São Paulo 
ternativa às práticas institucionalizadas que segregam, discriminam e invalidam as singularidades, subjetividades e potencialidades dos sujeitos. Tomadas pelo sofrimento, essas pessoas acabam na maioria das vezes não sendo compreendidas pela sociedade ou pela família, ficando confinadas nos manicômios, ou isoladas em seus núcleos familiares sem possibilidade de inserção social.

O Hospital-Dia recebe os portadores de sofrimento mental grave, que pela complexidade da forma de expressão do sofrimento não encontram meios terapêuticos suficientes na Unidade Básica de Saúde. O usuário chega até o Hospital-Dia encaminhado por outros equipamentos de saúde. Após a avaliação da equipe, prescreve-se o tratamento onde são definidas as atividades a serem realizadas e a freqüência na semana.

O Hospital-Dia da Mooca atende uma população de crianças que apresentam problemas de desenvolvimento na infância, juntamente com seus familiares, e que necessitam de atendimento intensivo em saúde mental. $\mathrm{Na}$ sua maioria, são casos de desestruturação psíquica da criança e/ou da família, com impossibilidade de organização social e inserção nas atividades do cotidiano, comumente diagnosticados como psicose infantil. As crianças permanecem na instituição durante um período do dia (manhã ou tarde), realizando, preferencialmente, atividades de caráter grupal em que utilizam-se técnicas que buscam resgatar suas potencialidades psíquicas.

Como forma de atender essa demanda, uma série de atividades é desenvolvida: triagem diagnóstica, atendimentos terapêuticos individuais, grupais e familiares, grupo de recepção, espaço livre, lanche, cuidados com a higiene de um modo geral, atividades culturais (comemoração de anivesários, passeios, festas da cultura), reunião com os pais, oficinas (história, arte, ecologia, cozinha, esportes, arte do movimento), visitas domiciliares, acompanhamento da criança na escola, reunião de equipe e supervisão.

A atividade cultural é um dos dispositivos institucionais para a clínica das psicoses. A partir dela podemos refletir sobre a relação das famílias com o Hospital-Dia. Para falarmos dessa construção é importante lembrar o que Freud pensava em relação ao tratamento da psicose.

Freud (1976b) considerava que o tratamento da psicose não era adequado à Psicanálise, ao método que era empregado, uma vez que o psicótico não estabelecia transferência. Mas enfatizava que, por meio de mudanças apropriadas no método, as psicoses poderiam ser tratadas. Fica-nos o convite e uma esperança para a busca de novas formas de tratamento para a psicose.

A partir do trabalho clínico das psicoses, estabelecemos que o processo de adoecer não se restringe ao sujeito que adoece, porta-voz do conflito, mas que sua enfermidade é um emergente de uma estrutura complexa, que é a família.

A origem e a história da família, sua função na organização social, seu lugar na constituição do psiquismo e da subjetividade são objeto de interrogação e interpretação de diferentes áreas do conhecimento. $\mathrm{O}$ instrumento de abordagem e compreensão da organização familiar há de ser sempre interdisciplinar.

A conduta do sujeito, por ser essencialmente relacional, somente pode ser decifrada na rede de vínculos que emerge e se configura. O sujeito se comporta em e para um contexto, onde sua experiência e conduta adquirem coerência e significação, ainda que pareçam incompreensíveis.

A princípio a enfermidade aparece 
como sinal e signo a se decifrar e como um emergente de um processo mais complexo que a produz. Aquilo que era tomado isoladamente, abstratamente, desviado da norma, inadequado e incoerente, quando visto na interioridade do contexto familiar, que neste momento gera a patologia, aparece agora revestido de coerência, incluído em uma lógica subjacente à interação desse grupo familiar. O sujeito assume dentro do grupo familiar um papel que preexiste a ele, isto é, que circulava no grupo previamente a seu nascimento e que lhe foi atribuído. Quando emerge a enfermidade no grupo familiar, o negado aparece redimensionado. Surge a loucura como o sinistro. O sinistro caracteriza-se pela aparição súbita $\mathrm{e}$ incontrolável daquilo que é o mais temido e terrorífico. O Hospital-Dia propõe-se a acolher isto.

As atividades do Hospital-Dia estão organizadas em duas direções: uma clínica (senso estrito) e outra clínica ampliada, isto é, do enfrentamento da loucura em sua vertente social, do excluído, daquilo que está fora. A criança psicótica, excluída do acesso à relação triangular, está fora da ordem estruturante da função paterna, havendo ausência de simbolização e perda do laço social.

Oferecer uma variada gama de atividades no Hospital-Dia possibilita grande potência clínica. "Potência clínica aqui entendida no sentido do paradigma possibilidade/probabilidade do qual nos fala Rotelli, rompendo com o modelo de causa e efeito" (Lima, 1992, p.111). Oferecemos uma rede de possibilidades aumentando a probabilidade de que algo novo se dê no mundo da criança. Oferecemo-nos com o corpo, com o olhar, com objetos, apostando que se possa criar um encontro de outra qualidade daquele experimentado até então pela criança.
A proposta da atividade cultural é ser um espaço onde estejam juntos técnicos, funcionários, crianças e familiares. O objetivo principal é a articulação da criança no circuito sócio-cultural, a integração das famílias, o exercício da cidadania, com atividades internas e externas ao Hospital-Dia. Os técnicos e os funcionários trabalham no sentido de fazer a ponte tratamento-socialização.

A idéia é que, para enfrentar a questão da exclusão que o estigma da loucura traz, temos que pensar não só na exclusão do paciente identificado, mas de toda a sua família. Propor às famílias que saiam com seus filhos acompanhados por nós é propor que se experimente e se vivencie uma situação nova para a maioria deles, rompendo com a idéia de que não é possível participar do circuito social, por terem filhos diferentes, doentes.

Inicialmente, a organização das atividades era feita por alguns profissionais da equipe técnica, sem a participação de funcionários da equipe de apoio e dos pais. Começamos a perceber a importância de envolvermos mais amplamente a equipe e os pais, pois a atividade necessitava ter um planejamento na escolha e organização das atividades. Isto modificou qualitativamente a realização das atividades, a implicação e a responsabilidade sobre o "sucesso" da atividade passou a ser compartilhado. A equipe criou um vínculo entre si e com os familiares, possibilitando que as atividades ocorressem com maior eficácia.

$\mathrm{Na}$ equipe, a atividade cultural foi uma convivência, às vezes pacífica, às vezes conflituosa, de várias abordagens, visões e formas de pensar. A atividade cultural começou alguns meses após o início do funcionamento do HospitalDia. Discutimos a viabilidade, possibilidade e pertinência de um espaço mais aberto para as crianças, em que pu- 
dessem ser incluídas atividades do cotidiano e da cultura (música, teatro, circo, passeios, comemorações de aniversários). Havia divergências na equipe quanto à inclusão dos familiares nesse tipo de atividade.

A Atividade Cultural ocorria às sextas-feiras, com a participação de todas as crianças, da manhã e da tarde. Basicamente dividia-se -em três tipos: aniversários, passeios e festas da cultura (carnaval, Páscoa, festa junina, dia das crianças, Natal). O objetivo era que cada vez mais as familias pudessem se apropriar daquele espaço, participando da organização e da atividade, enquanto a equipe ficava mais no suporte e na referência. Os pais conseguiam verbas para complementar as atividades. O importante disto tudo não era só a festa ou o passeio em si, mas o que foi se criando na relação da família com a criança e com o Hospital-Dia. É interessante assinalar que as festas não tinham "cara de festa de instituição", em que o clima ficava "meio forçado". Pelo contrário, havia um clima de espontaneidade, criação, respeito aos limites das crianças e valorização de seus recursos. A maior parte das crianças nunca havia comemorado seu aniversário. Seria só por falta de recursos da família?

Percebemos que o lugar de doente e impossibilitado que a criança ocupa dificulta que a família comemore um nascimento e invista nisto. Poder mexer nesse nódulo da família é muito mais que impor uma norma, ou iludir a família sobre seu filho, é antes dar-lhe possibilidades de se perguntar sobre a criança, viver o brincar, comemorar a vida e os eventos, tendo um filho do jeito que é, não continuando a carregar um "morto-vivo", mas ir experienciando a vida e as dificuldades que esta apresenta.

Contávamos com o desejo de alguns profissionais que acreditavam muito na importância de a família experienciar situações que não tinha possibilidade de viver e a partir daí ampliar o seu pertencimento ao mundo e cultura.

As ações terapêuticas revertem muitas vezes na confiança da família nos profissionais e em suas potências enquanto pais, experienciadas na situação. As atividades interna e externa ao Hospital-Dia têm o objetivo de possibilitar a criação de um espaço que potencialize a família para exercer suas funções fora do Hospital-Dia, para além do tratamento, de forma que as situações do cotidiano possam ser realizadas pela família dentro do seu circuito social.

Podemos pensar que este espaço permite a cada membro da família experimentar-se em novas relações e também transformar as relações entre eles. As mães podem vivenciar situações de brincadeiras, por exemplo de passear, que nunca tiveram, porque nunca foram passeadas. Podemos pensar também, numa perspectiva winnicottiana, em que aos poucos vai se dando o brincar, o brincar compartilhado, e deste vão emergindo as experiências culturais.

Já fomos a vários parques. Houve várias experiências, às vezes tranqüilas, às vezes tumultuadas: uma criança entrou em crise e bateu na mãe em público, requerendo intervenção com a criança, com a mãe, com os outros participantes da atividade e com os usuários do parque; uma família brigou na frente de todos; e a equipe discutiu durante uma atividade.

A nossa presença ao lado das famílias traz muitas questões quanto ao manejo, pois as intervenções que fazemos são em ato. Por exemplo, a mãe que "gruda" no filho durante o passeio, limitando sua possibilidade de experimentação, faz-nos pensar e fazer uma intervenção no sentido de separá-la do filho por algum momento, avaliando-se a posteriori os efeitos da intervenção. $\mathrm{O}$ 
que ocorre num passeio pode ser trabalhado posteriormente na terapia familiar, nos espaços em que a criança circula no Hospital-Dia. Ocorriam, muitas vezes, por parte dos profissionais, ações sintônicas ou divergentes em relação à condução do tratamento. Nas reuniões clínicas da equipe, e nas específicas da atividade cultural, discutia-se a pertinência ou não das intervenções.

Experimentávamos com as famílias as formas possíveis de estar no campo social. Compartilhávamos com as famílias as suas dificuldades, intervindo no sentido de a criança poder estabelecer um laço novo com a família e com o social.

O dentro e o fora nesta atividade não é apenas a questão de ser interno ou externo ao espaço físico do Hospital-Dia, mas a criação de um dispositivo que se expande além do tratamento no Hospital-Dia, no âmbito do cotidiano familiar.

As crianças vão mudando sua percepção, descobrindo maneiras de ser, brincando em alguns momentos e, em outros, ficando sós. Neste sentido, consideramos importante elas estarem articuladas no circuito social, o que não significa estarem necessariamente inseridas nesse circuito. A inserção está relacionada com adaptação, com cobranças para que a criança seja igual e se encaixe num sistema preestabelecido. A articulação, por outro lado, é a criança perceber seus limites e isto não paralisá-la nem aterrorizá-la, mas ser uma forma de caber no mundo. Mesmo que com um pé no seu próprio mundo, ela já pode fazer parte do circuito social.

As atividades não tinham um cunho de repetir automaticamente os eventos escolares ou cotidianos simplesmente. Visavam criar uma rede de sustentação em que a pertença da criança e de sua família iam se tecendo.
Além do direito à cidadania, enquanto uma questão político-social, estávamos tentando construir e manter um dispositivo que propiciava novas experiências e possibilitava às famílias o pertencimento à cultura humana, que é um grande coadjuvante do tratamento, pois nela está simbolizada boa partè da experiência coletiva.

\section{A INCIDÊNCIA DO DISPOSITIVO INSTITUCIONAL NA CLÍNICA DAS PSICOSES NA INFÂNCIA}

Uma das características dos dispositivos clínicos institucionais é refletir uma certa concepção de cura, que acaba por determinar não só o funcionamento das instituições, mas também a prática clínica dos profissionais que nela circulam, mesmo que esta prática não seja adotada intencionalmente.

É curioso notar que, embora a noção de cura seja polêmica, a maioria das concepções tem como denominador comum uma ação que visa a uma "retificação" da inserção do sujeito na cultura, seja ela social, educacional ou familiar. Isto quer dizer que qualquer modalidade de tratamento adotada para as psicoses, inclusive as da infância, implica um tipo de construção.

Embora o trabalho analítico parta, qualquer que seja a natureza da queixa, da posição que o sujeito ocupa na sua linhagem, isto não quer dizer que a análise das neuroses e das psicoses seja manejada da mesma maneira. Na neurose, encontramos um sujeito capturado por uma fantasia construída que representa a marca de inscrição na sua linhagem. Na psicose, a recusa a esta inscrição leva a uma tentativa incessante, mas 
sem sucesso, de construir o lugar destinado pela linhagem, processo ao qual chamamos delírio.

Assim, a dimensão do desejo será introduzida de maneira distinta em cada caso: na clínica da neurose, o sujeito é convocado a se implicar na fantasia que construiu sobre a sua posição na linhagem; enquanto na clínica da psicose, o desejo de introdução na linhagem ainda precisa ser construído. Ao pensarmos na possível análise desta última, de uma certa maneira, estaremos nos debatendo com o fato de, muitas vezes, os ideais e anseios marcados pela linhagem do sujeito se traduzirem justamente na impossibilidade de conferir-lhe um lugar desejante. Seja qual for a perspectiva clínica, a psicanálise sempre inclui a dimensão do desejo, o que necessariamente introduz na análise uma dimensão ética.

Para compreendermos a estrutura da psicose, é necessário abordarmos a noção de sujeito em psicanálise, que não se refere a um sujeito enunciante, mas a um lugar enunciado, que lhe configura, antes de mais nada, o estatuto de assujeitamento a uma rede histórica que o captura não só pelos temores, como pelos anseios e ideais parentais. Ao mesmo tempo que recaem sobre o indivíduo, levando-o a formar uma imagem ideal de si, estas marcas inscrevem-lhe um destino.

$\mathrm{Na}$ estrutura psicótica, esta inscrição é rejeitada e o sujeito é excluído da linhagem, ficando privado de sua marca de alteridade. Cabe ressaltar que este processo não é fruto de volição consciente daqueles que se encarregaram dos cuidados da criança, mas de um processo lógico, apontado pelo sentido histórico da linhagem. Neste contexto, o delírio é uma colagem construída do sujeito a partir das qualidades imagéticas dos significantes de sua própria história, construção que pode ter eficácia na medida em que o enlaça nas suas relações sociais. Diferentemente do adulto, o delírio de algumas crianças aparece sob a forma de ato.

O que me interessa refletir aqui é como os dispositivos montados para esta construção incidirão no psiquismo. Seria ingênuo pensarmos que um dispositivo por si só é adequado e bastaria para o sucesso. Temos o compromisso ético de nos perguntarmos a serviço do que está o dispositivo. A construção é, de fato, uma simbolização do lugar ocupado na linhagem ou é mera adaptação? O dispositivo atende às necessidades do sujeito ou é conivente com uma demanda de mantê-lo exatamente na mesma posição?

O Hospital-Dia Infantil da Mooca tem, como uma de suas particularidades, inserir a família no tratamento da psicose na infância. Tal procedimento está embasado na convicção de que não é possível uma clínica da psicose infantil, sem que se trate de uma questão referente à filiação do sujeito e sua herança familiar, isto é, há de se levar em conta o projeto a partir do qual a criança foi concebida.

Gostaria de ilustrar estas questões através de um caso clínico atendido nesse Hospital-Dia Infantil: 
A mãe de Robson morreu no parto. Robson foi criado pela avó e tias maternas: a tia mais velha, A.., que se responsabilizou por seus cuidados, e a tia B., sua tutora jurídica. A mãe de Robson era a filha mais nova. Nesta família, nas duas gerações anteriores, todos os filhos homens haviam falecido. A. nunca se casou ou teve uma relação conjugal e as outras tias de Robson nunca tiveram relações duradouras, mas tiveram filhos.

Quando chegou ao H.D., Robson não se comunicava nem fazia contato, tinha apenas uma fala ecolálica, em geral, de coisas ouvidas na TV. Passava o dia desenhando ônibus na lousa. Desde as entrevistas iniciais, Robson colocava-se na frente dos familiares e repetia monocordicamente a seguinte pergunta: "Quem matou Jorge Tadeu?"3, ao que eles respondiam da mesma forma: "Quem matou Jorge Tadeu?" Isto se estendia por muito tempo mesmo quando interrompidos por nós.

Robson nunca conheceu seu pai, Jorge. Uma vez este lhe mandou um cartão de Natal, que "sem querer" foi jogado fora por A.

A família nunca comemorou seu aniversário, pois essa ocasião sempre era motivo de luto. A. tinha a mãe de Robson como uma filha. Robson veio a ter sua primeira festa de aniversário no H.D., na comemoração dos "aniversariantes do mês", da Atividade Cultural do Hospital-Dia.

Além de ser inédito Robson ter, pela primeira vez em sua vida, uma festa de aniversário, uma comemoração de seu nascimento, da sua existência, este evento propiciou que no atendimento familiar (individual) se falasse do nascimento de Robson e do luto de sua mãe. Depois da festa no hospital, também houve pela primeira vez um "bolinho" na sua casa.

No aniversário seguinte, encon- tramos Robson numa situação bem distinta: desenhava e pedia o que queria de aniversário. Dizia querer um bolo "de Prestígio" (chocolate e coco). Na oficina de cozinha, teve a oportunidade de fazer o seu bolo "de Prestígio" e cantar parabéns no lanche. Foi até a cozinheira do hospital, (nossa tia Nastácia!) e pediu bolo "de Prestígio". Fez o mesmo pedido em sua casa.

Como naquele ano, em função das mudanças administrativas, estávamos com problemas de fornecimento de alimentos no hospital, era costume a cotização entre os familiares dos aniversariantes do mês. Esse era um trâmite entre a equipe da cozinha, coordenadores da oficina cultural e famílias. Nem sempre o técnico de referência sabia se ia precisar comprar alguma coisa e quanto. Robson começou a ficar muito angustiado naquela semana, acentuando seus comportamentos de estereotipia (morder as mãos, se estapear no rosto $e$ boca). A. anuncia que Robson não teria festa de aniversário em casa, pois eles só teriam dinheiro para um bolo e ela preferia fazer a festa dele no hospital.

Vou interromper o relato neste ponto e retomar a nossa discussão, pois vemos, justamente nesta situação quase banal e cotidiana, o tangenciamento do sujeito em sua posição, mesmo que esta seja a de exclusão. O manejo do dispositivo institucional é, de certa forma, decisivo.

Como lidar com o movimento de A.? Era um movimento de exclusão? Aliás, cabe sublinhar a curiosa posição de A., pois ao mesmo tempo que ela age, dá a condição de interceder por ela, de interrogá-la.

Volta-se à mesma questão: Robson só tem lugar fora, nunca dentro. O tema do "por que ele não pode ser comemorado?" prossegue nas sessões familiares. Onde ele precisa mais do bolo de prestígio? No H.D. ele já havia feito o seu 
próprio bolo. Então, a questão era o prestígio de A. na comunidade do H.D., frente aos outros pais e técnicos? Esta preocupação de fato incluía Robson? Tinha a ver com o lugar de A. como mãe ou de coleguinha das mães dos outros usuários? Neste sentido, poderia haver até uma "competição" com o sobrinho, pois uma das queixas de A. é que ela sempre trabalhou e cuidou das irmãs para ajudar a mãe dela e, por isto, não se casou ou teve filhos. Este é o campo que chamei acima de dimensão ética da psicanálise - o campo do desejo.

A resolução tomada foi de que o bolo de Robson, na festa do hospital, seria aquele que estivéssemos em condições de produzir. A festa do hospital não seria pretexto para ele não ter sua festa em casa.

Este exemplo, embora simples, ilustra bem as fendas pelas quais o dispositivo institucional corre. Acho-o didático e os convido, a partir dele, a refletir sobre a prática institucional frente à complicada questão do delírio, das famílias, das equipes e dos modelos institucionais.

\section{REFERÊNCIAS BIBLIOGRÁFICAS}

FREUD, S. (1976a). Sobre o narcisismo: uma introdução. In: Obras

Psicológicas Completas. ESB. Rio de Janeiro: Imago Editora, v. XIV. [1914] (1976b). Sobre a psicoterapia. In: op.cit., v. VII. [1905]

JERUSALINSKY, A. (1984). Psicanálise do autismo. Porto Alegre: Artes Médicas.

LIMA, E. A. (1992). Uma experiência de atividade cultural em um HospitalDia Infantil. In: Encontro de Hospitais-Dia do Município de São Paulo, 1. Secretaria Municipal de Saúde de São Paulo.

PENOT, B. (1992). A infância do delírio. In: Figuras da recusa: aquém do negativo. Porto Alegre: Artes Médicas.

QUINET, A. (1993). As 4 + 1 condiçôes da análise. Rio de Janeiro: Jorge Zahar.

\section{NOTAS}

1 Devido à implantação do PAS (Plano de Atendimento à Saúde) no Município de São Paulo, a maior parte dos profissionais foi transferida para outros locais, havendo mudança no gerenciamento dos equipamentos.

2 A estrutura do modelo alternativo proposto foi: Hospital-Dia, Unidade Básica de Saúde (UBS), Centro de Convivência e Cooperativa (CECCO), Lar Abrigado, Hospital Geral (Emergência Psiquiátrica, Enfermaria Psiquiátrica, Interconsulta e Psicologia Hospitalar).

3 Chamada de novela de horário nobre da TV na época do atendimento. 